\title{
Extraction and Evaluation of Fatty Acid Compositon of Orbignya phalerata Martius Oils (Arecaceae) from Maranhão State, Brazil
}

\author{
Débora S. Santos, ${ }^{a}$ Ilna G. da Silva, ${ }^{a}$ Bruno Q. Araújo, ${ }^{b}$ Cícero A. Lopes Júnior, ${ }^{b}$ \\ Nayana B. N. Monçãoo, ${ }^{b}$ Antônia M. das G. L. Citó, ${ }^{b}$ Mércia H. S. L. de Souza, ${ }^{c}$ \\ Maria do D. S. B. Nascimento ${ }^{d}$ and Maria Célia Pires Costa ${ }^{*, a}$
}
${ }^{a}$ Departamento de Química e Biologia, Universidade Estadual do Maranhão (UEMA), Campus Universitário Paulo VI, 65055-970 São Luís-MA, Brazil

${ }^{b}$ Departamento de Química, Universidade Federal do Piauí (UFPI), Campus Ministro Petrônio Portela, 64049-550 Teresina-PI, Brazil

${ }^{c}$ Laboratório de Microbiologia, Centro Universitário do Maranhão, 65075-120 São Luís-MA

${ }^{d}$ Laboratório de Imunologia Básica e Aplicada, Universidade Federal do Maranhão, Campus do Bacanga, 65085-580 São Luís-MA, Brazil

\begin{abstract}
A composição de ácidos graxos de seis amostras de Orbignya phalerata de diferentes cidades do estado do Maranhão foi estudada. Os óleos foram extraídos utilizando extrator Soxhlet por duas metodologias e a composição de ácidos graxos foi avaliada por cromatografia gasosa-espectrometria de massas (CG-EM). O teor da fração de lipídios revelou que o solvente usado influencia na extração, sendo a maior porcentagem obtida com hexano. O teor de lipídios variou de 62,46-67,45\%, com predominância de ácidos graxos saturados $(80,32-87,80 \%)$, principalmente ácido láurico (C12:0) com percentual de 44,86-52,15\%. A análise multivariada mostrou a distribuição das amostras de $O$. phalerata em três regiões distintas e sugere que a composição química dos óleos pode estar associada com a sua localização geográfica. Estes dados mostram o conhecimento da biodiversidade de ácidos graxos de $O$. phalerata entre as diferentes regiões do estado do Maranhão.
\end{abstract}

The fatty acid composition of six Orbignya phalerata samples of different cities from Maranhão State (Brazil) was studied. The oils were extracted by two methods using Soxhlet extractor and the fatty acid composition was evaluated by gas chromatography-mass spectrometry (GC-MS) analysis. The lipid fraction content showed that the solvent used influences lipid extraction, the highest percent was obtained with hexane. Lipid content ranged from $62.46-67.45 \%$, with predominance of saturated fatty acids (80.32-87.80\%), mainly lauric acid (C12:0) with 44.86 to $52.15 \%$. Multivariate analysis showed the distribution of $O$. phalerata samples into three distinct regions and suggests that the oil chemical composition may be associated with their geographic location. These data show knowledge of the biodiversity of $O$. phalerata fatty acids among the different regions of the Maranhão State (Brazil).

Keywords: babassu oil (Orbignya phalerata Martius), fatty acids, GC-MS, multivariate analysis

\section{Introduction}

The babassu palm, Orbignya phalerata Martius synonymy O. martiana, belongs to Arecaceae (Palmae)

*e-mail: celiacosta@prof.elo.com.br family. It is the most widespread, morphologically variable and economically important species ${ }^{1}$ distributed in some Brazilian states: Maranhão, Piauí, Goiás, Tocantins, Pará and Mato Grosso. Exploitation of $O$. phalerata palm tree is a well-established and secular activity in Brazil for use as food supply, production of household objects, raw material for building homes and biomass. ${ }^{2}$ 
The babassu fruits are oval and elongated weighing $90-280 \mathrm{~g}$. The fruit contains epicarp (11\% in mass), mesocarp (23\% in mass) and endocarp (59\% in mass) with 3-4 nuts (7\% in mass), which are rich in triacylglycerols $(>60 \%$ in mass), with predominance of lauric acid (C12:0) and minerals (Al, Ba, $\mathrm{Ca}, \mathrm{Cu}, \mathrm{Fe}, \mathrm{K}, \mathrm{Mg}, \mathrm{Mn}, \mathrm{Sr}$ and $\mathrm{Zn}$ ). ${ }^{2,3}$ The babassu nut is one of the non-timber products that stood out the most out in production value, concentrating the total of extractive production in the Brazilian Northeast (99.4\%), making the Maranhão State the largest producer of babassu nuts, corresponding to $54.6 \%$ of national output in $2010 .^{4}$

According to the Brazilian Agricultural Research Corporation (EMBRAPA), ${ }^{5}$ the economic potential of babassu fruits, especially its nuts, as well as its oil, is largely used in pharmaceuticals, cosmetics, food and medicinal uses. Souza et al. ${ }^{6}$ reported that in the traditional medicine of Northeast Brazil, babassu-derived products are mainly used in some diseases, such as inflammation process. Although, babassu oil presents several industrial applications, for example biodiesel production, ${ }^{7}$ the chemical knowledge is necessary to ensure quality and better exploitation of biomass.

Previous articles describe the use of gas chromatography (GC) and gas chromatography-mass spectrometry (GC-MS) for oil chemical constituent identification. ${ }^{8}$ This procedure has been successfully applied to the identification of substances of structures known, because in most cases, all data generated can be compared directly with the retention time values obtained in columns with different polarities and mass spectra of constituents published in computerized libraries. Advances in gas chromatography (GC) have promoted the study of lipids and provided knowledge of the fatty acid composition in a short period of time. .10

The objective of the present study was to evaluate the chemical composition of babassu nut oils from samples of O. phalerata Mart. collected from different cities of Maranhão State (Brazil). The fatty acid composition by GC-MS was evaluated using methods of principal component analysis (PCA) and hierarchical cluster analysis (HCA).

\section{Experimental}

\section{Materials}

The solvents and reagents used were of analytical grade. The reference standard of fatty acid methyl esters (FAME, $\mathrm{C}_{4}-\mathrm{C}_{24}$ ) for GC was purchased from Supelco (St. Louis, MO, USA). The thin layer chromatograms (TLC) were made on glass support with $0.25 \mathrm{~mm}$ thickness of stationary phase containing silica gel $60 \mathrm{G}$ Sigma. The TLC plates were developed by iodine vapors.

\section{Babassu nut samples}

O. phalerata nut samples were collected in six cities of Maranhão State: São Luís (SL), Imperatriz (IMP), Penalva (PEN), Esperantinópolis (EPT), Fortuna (FOR) and Riachão (RIA), which corresponded to the ecological regions: Litoral, Pre-Amazon, Baixada, Cocais, Transition area (Cerrado/ Cocais) and Cerrado, respectively (Table 1, Figure 1). The babassu fruit selection was aleatory. At the moment of

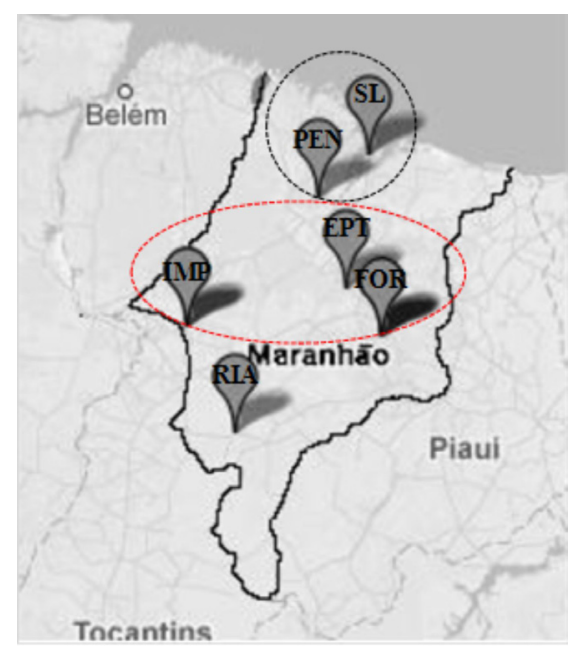

Figure 1. Distribution of six $O$. phalerata nuts from Maranhão State (Brazil) which originated the samples in Table 1. São Luís (SL), Esperantinópolis (EPT), Fortuna (FOR), Riachão (RIA), Penalva (PEN) and Imperatriz (IMP). The dash lines were marked on the basis in high correlation 3D PCA plot (Figure 3).

Table 1. Localization and geographical coordinates of O. phalerata nut sampling sites in Maranhão State, Brazil

\begin{tabular}{lcccc}
\hline City & Latitude S; Longitude W & Area / $\mathrm{km}^{2}$ & Climate & Region \\
\hline São Luís & $-02^{\circ} 31^{\prime} 47^{\prime \prime} ; 44^{\circ} 18^{\prime} 10^{\prime \prime}$ & 827.1 & tropical, hot and humid & Litoral \\
Imperatriz & $-05^{\circ} 31^{\prime} 35^{\prime \prime} ; 47^{\circ} 29^{\prime} 30^{\prime \prime}$ & 1367.9 & tropical sub-humid & Pre-Amazon \\
Penalva & $-03^{\circ} 17^{\prime} 39^{\prime \prime} ; 45^{\circ} 10^{\prime} 25^{\prime \prime}$ & 785.6 & tropical humid & Baixada \\
Esperantinópolis & $-04^{\circ} 52^{\prime} 00^{\prime \prime} ; 44^{\circ} 42^{\prime} 30^{\prime \prime}$ & 480.9 & tropical sub-humid & Cocais \\
Fortuna & $-05^{\circ} 44^{\prime} 00^{\prime \prime} ; 44^{\circ} 09^{\prime} 30^{\prime \prime}$ & 695.0 & tropical, dry season & Transition Area (Cerrado/Cocais) \\
Riachão & $-07^{\circ} 21^{\prime} 43^{\prime \prime} ; 46^{\circ} 37^{\prime} 02^{\prime \prime}$ & 6373.2 & tropical, dry season & Cerrado \\
\hline
\end{tabular}


collection, the nuts were separated from babassu fruits and packed in hermetically sealed flasks under refrigeration.

\section{Oil extraction}

The babassu oils $(5.0 \mathrm{~g})$ were extracted using two methods. Method A: ${ }^{11}$ extraction with petroleum ether, in accordance with the analytical protocol of Adolfo Lutz Institute (IAL). Method B:12 extraction with $n$-hexane according the IUPAC procedure. The nuts were crushed in rotor mills (Tecnal model TE 651) and dried for $2 \mathrm{~h}$ at $105{ }^{\circ} \mathrm{C}$. The dried samples were weighed on analytical balance and inserted in Soxhlet extraction system (Tecnal model TE-044-8/50) for determination of lipid contents. The solvent of lipid fraction was removed by evaporation under reduced pressure in a rotary evaporator. The oils obtained were weighed until constant weight in dessicator, and then the oil yield was calculated. Oil yield $(\%)$ was calculated by the followed equation:

Oil yield $=\frac{\text { Oil weight }}{\text { Nut weight }} 100$

All procedures were performed in triplicate.

\section{Preparation of fatty acid methyl ester (FAME)}

FAME was obtained according method described by Hartman and Lago ${ }^{13}$ with some modifications. An amount of $500.0 \mathrm{mg}$ of babassu oil was added to $5.0 \mathrm{~mL}$ of $0.50 \mathrm{~mol} \mathrm{~L}^{-1} \mathrm{NaOH}$ in methanol and the mixture was heated under reflux for $5 \mathrm{~min}$. Then, $15 \mathrm{~mL}$ of esterification reagent (2.0 g of ammonium chloride, $60.0 \mathrm{~mL}$ of methanol and $3.0 \mathrm{~mL}$ of concentrated sulfuric acid a mixture previously prepared for ca. $15 \mathrm{~min}$ ) were added, the mixture was heated under reflux for $15 \mathrm{~min}$ and next transferred to a separation funnel with $25.0 \mathrm{~mL}$ of hexane and $50.0 \mathrm{~mL}$ of deionized water. The procedure was repeated. After agitation and phase separation, the aqueous phase was discarded and organic phase was dried with anhydrous sodium sulfate. Then, it was performed filtration through Whatman No. 1 filter paper and the organic phase collected. The conversion of FAME was evaluated by TLC using silica gel as stationary phase and $n$-hexane/EtOAc (95:5) as eluent, the chromatographic plates were revealed by iodine vapors. FAME was analyzed by injection into a GC-MS system.

\section{Analysis of FAME by gas chromatography-mass spectrometry (GC-MS)}

FAME was analyzed with the Shimadzu GC-17A gas chromatograph coupled to a Shimadzu mass spectrometer model QP5050A equipped with HP-1MS capillary column ( $100 \%$ methylpolysiloxane, $30 \mathrm{~m}$ long $\times 0.25 \mathrm{~mm}$ i.d $\times 0.25$ $\mu \mathrm{m}$ film thickness), after injection of $1 \mu \mathrm{L}$ of FAME hexane solution $\left(5.0 \mathrm{mg} \mathrm{mL}^{-1}\right)$. Injector and auxiliar temperature was at $300^{\circ} \mathrm{C}$. Programming of the column was as follows: initial temperature $80.0^{\circ} \mathrm{C}$ for $1 \mathrm{~min}$, rate of $4.0^{\circ} \mathrm{C} \mathrm{min}{ }^{-1}$ up to $200{ }^{\circ} \mathrm{C}$, held for $2 \mathrm{~min}$, and heating rate of $12{ }^{\circ} \mathrm{C} \mathrm{min}{ }^{-1}$ up to $300{ }^{\circ} \mathrm{C}$, held for $8 \mathrm{~min}$. The mass detector was run in scan mode, acquisition time of $41.33 \mathrm{~min}$ and solvent-delay time was $8 \mathrm{~min}$, mass range $40-450 \mathrm{Da}$, electron ionization (EI) at $70 \mathrm{eV}$, voltage detector at $1.3 \mathrm{kV}$, quadrupole mass analyzer and $1.5 \mathrm{~mL} \mathrm{~min}^{-1}$ helium carrier gas-flow.

FAME was identified by comparison of mass spectra of the total ion chromatogram with those of Wiley 229 library using similarity index (SI) and comparison of retention times of peaks with authentic FAME. Fatty acid methyl esters were quantified as percentages (\%) of the total methyl ester peak areas.

\section{Statistical analyses}

The relationship between the samples and analyzed variables was established by application of multivariate exploratory analysis using HCA with dendrogram plot construction to visualize similarities between samples, and PCA to identify the variables that influence the group formation. The statistical procedures were performed using the software program SPSS 15.0 (Statistical Package for the Social Sciences).

\section{Results and Discussion}

In this study, babassu nut oils were extracted from O. phalerata fruits originated from six cities of Maranhão State. A list of localization and geographical coordinates of $O$. phalerata nuts was shown in Table 1 . The oil contents of babassu nuts (O. phalerata) obtained from the extraction methods A and B (Table 2) per each $5.0 \mathrm{~g}$ sample ranged around the averages: $3.29-3.32 \mathrm{~g}$ and $2.56-2.82 \mathrm{~g}$, which is related to the oil yields $62.46-67.45 \%$ and $46.79-61.16 \%$, respectively. The selected methodologies were to yield a result within the related range of lipid yields, according to the literature, Gunstone and Norris, ${ }^{14}$ Peixoto, ${ }^{15}$ Soler et al.${ }^{16}$ and Picciani, ${ }^{17}$ in which the oil yields from the babassu nuts were $60-65 \%, 65,60-68 \%, 65-68 \%$, respectively.

The oil yield obtained using method A with babassu nuts of the Imperatriz (IMP), Esperantinópolis (EPT), Riachão (RIA), São Luís (SL) and Fortuna (FOR) (65.17, 65.17, 65.81, 66.45 and $67.45 \%$ ) are in accordance with Soler et al..$^{16}$ and Picciani. ${ }^{17}$ The Penalva City (PEN) $(62.46 \%)$ is within the range reported by Gunstone and Norris ${ }^{14}$ and Soler et al. ${ }^{16}$ 
Table 2. Oil contents (\%) of babassu nuts (Orbignya phalerata Mart.) from Maranhão State (Brazil) obtained by the protocols of IAL (method A) and IUPAC (method B)

\begin{tabular}{lcc}
\hline \multirow{3}{*}{ Sample } & Method A & Method B \\
\cline { 2 - 3 } & $\begin{array}{c}\text { Mean } \pm \text { SD / \% } \\
(\mathrm{CV} / \%)\end{array}$ & $\begin{array}{c}\text { Mean } \pm \text { SD / \% } \\
(\mathrm{CV} / \%)\end{array}$ \\
\hline São Luís & $66.45 \pm 0.21$ & $51.36 \pm 1.05$ \\
& $(0.31)$ & $(2.03)$ \\
Imperatriz & $65.17 \pm 0.44$ & $61.16 \pm 2.43$ \\
& $(0.67)$ & $(3.97)$ \\
Fortuna & $67.45 \pm 0.04$ & $55.94 \pm 2.66$ \\
& $(0.06)$ & $(4.75)$ \\
Esperantinópolis & $65.17 \pm 0.44$ & $58.80 \pm 1.16$ \\
& $(0.67)$ & $(1.97)$ \\
Penalva & $62.46 \pm 1.36$ & $46.79 \pm 5.02$ \\
& $(2.17)$ & $(10.72)$ \\
Riachão & $65.81 \pm 1.03$ & $56.38 \pm 0.11$ \\
& $(1.56)$ & $(0.20)$ \\
\hline
\end{tabular}

SD: standard deviation; $\mathrm{CV}$ : coefficient of variation.

In method B, the oil yield of babassu nuts from Imperatriz presented a percentage equal to $61.16 \%$, which is consistent with Gunstone and Norris ${ }^{14}$ and Soler et al. ${ }^{16}$ However, the babassu nut oil yield from other cities when method B was employed showed lower values than those reported in the literature. ${ }^{14-17}$

The extraction methods A and B of the babassu nut samples were reproductive with coefficient of variation (CV) less than 5\%, except extraction of the Penalva sample by Method B which presented highest CV 10.72\% (Table 2). Moreover, the method A showed the highest oil contents when compared to method B. The lipid concentrations were statistically different $(p<0.05)$ between the methods.

The oil yield from the nuts depends on the nature of the solvent, the temperature of extraction, seed particle, among other factors. The larger amount of lipid extracted from babassu nuts by Soxhlet extraction with hexane $(\operatorname{method} \mathrm{A})$ in contrast with petroleum ether (method B) was due to a better solubility of non-polar lipids in hexane. ${ }^{18,19}$ Therefore, the extraction method A was the most appropriate methodology for obtainment of triacylglycerols from babassu nuts.

The lipid fraction extracted using method A was subjected to hydrolysis reaction to free fatty acids (FFA). Then, FFA was submitted to esterification reaction using $\mathrm{H}_{2} \mathrm{SO}_{4} / \mathrm{NH}_{4} \mathrm{Cl} /$ methanol resulting in their respective fatty acid methyl esters. Typical chromatogram obtained from GC-MS analysis of FAMEs from babassu nuts are presented in Figure 2. As it can be observed, the chromatographic profile showed smooth base line and good reproducibility due to less variation to retention time.

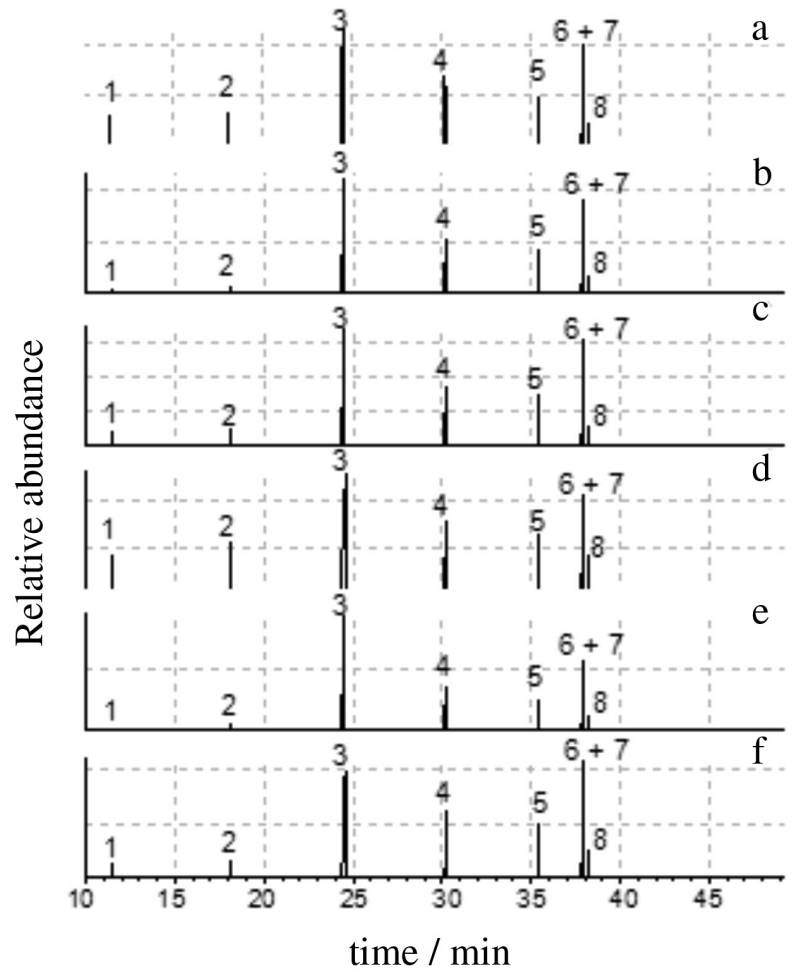

Figure 2. GC-MS chromatograms using HP-1MS capillary column of the fatty acid methyl ester composition of babassu nut oils from Cities of the Maranhão State (Brazil): (a) São Luís (SL), (b) Esperantinópolis (EPT), (c) Fortuna (FOR), (d) Riachão (RIA), (e) Penalva (PEN) and (f) Imperatriz (IMP). Fatty acid methyl esters: 1- methyl caprylate (C8:0), 2-methyl capricate (C10:0), 3- methyl laurate (C12:0), 4- methyl myristate (C14:0), 5- methyl palmitate (C16:0), 6- methyl linoleate (C18:2), 7- methyl oleate (C18:1) and 8- methyl stearate (C18:0).

The characteristic fragment ions of mass spectra by electron ionization $(\mathrm{EI}, 70 \mathrm{eV}$ ) of fatty acid methyl esters (FAME) are: (1) methyl caprylate (C8:0) EIMS: [M+] 158 (0.34 \%), 87 (36\%), $74(100 \%), 55(29 \%)$ and $41(42 \%)$; (2) methyl capricate (C10:0) EIMS: [M+]: $186(0.51 \%)$, $143(9 \%) 87$ (43\%), $74(100 \%), 55(31 \%)$ and $41(51 \%)$;

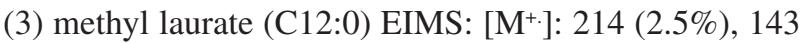
$(18 \%) 87(84 \%), 74(100 \%), 55(67 \%)$ and $41(78 \%)$; (4) methyl myristate (C14:0) EIMS [M+]: 242 (1.4\%) 87 (34\%), 74 (100\%), 55 (60\%) and $41(43 \%)$; (5) methyl palmitate (C16:0) EIMS: [M+]: $270(2.0 \%) 87(65 \%)$, 74 (100\%), 55 (44\%) and 41 (60\%); (6) methyl linoleate

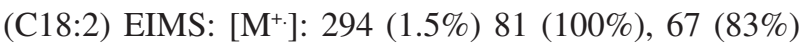
$55(75 \%)$ and 41 (60\%); (7) methyl oleate (C18:1) EIMS: [M+. 296 (1.5\%), 264 (5\%), 110 (10\%), 55 (100\%) and 41 (95\%); (8) methyl stearate (C18:0) EIMS: [ $\left.\mathrm{M}^{+}\right]$: 294 (1.5\%), 255 (5\%), 143 (11\%), 87 (67\%), 74 (100\%), 55 $(53 \%)$ and $41(69 \%)$. The typical fragmentation of methyl esters (the McLafferty rearrangement ion is characterized by bond cleavage of $\beta$ linkage at carbon 2 and 3 from carbonyl and migration of $\mathrm{H}$ for the carbo-methoxy group) presents $\mathrm{m} / z 74\left[\mathrm{H}_{3} \mathrm{COCOHCH}_{2}^{+}\right]$in the mass spectra. ${ }^{20}$ 
However, the McLafferty ions $(\mathrm{m} / \mathrm{z}$ 74) are only abundant in fragmentation of methyl esters of saturated fatty acids. In contrast, the mass spectrum of methyl esters of unsaturated fatty acids shows hydrocarbon ions with $m / 255\left(\left[\mathrm{C}_{\mathrm{n}} \mathrm{H}_{2 \mathrm{n}-1}\right]^{+}\right)$ to methyl esters of monoenoic fatty acids as the base peak and hydrocarbon ions $(\mathrm{m} / \mathrm{z}, 67,81,95,109$, etc.) of general formula $\left(\left[\mathrm{C}_{\mathrm{n}} \mathrm{H}_{2 \mathrm{n}-3}\right]^{+}\right)$are predominant in the lower mass range to methyl esters of dienoic fatty acids.

In the chromatographic analysis, it was identified eight fatty acid methyl esters in $O$. phalerata nuts from Maranhão State, as can be seen in the Table 3. The results were expressed as fatty acid composition (\%) determined by GC-MS peak integration, and for chemical constituent identification, it was used the similarity index (Wiley 229 library) and retention time of methyl esters of the FAME standard mixture.

The babassu oil ( $O$. phalerata) showed a high percent of saturated fatty acids, ranging from 80.32 to $87.80 \%$. The results also showed that there was no difference in types and/or classification of fatty acids among the cities in the study. All samples presented the same chromatographic profiles of fatty acids with an even number of carbon atoms, with the presence of three medium chain saturated fatty acids (C8:0, C10:0 and C12:0), three long chain saturated fatty acids (C14:0, C16:0 and C18:0) and two unsaturated fatty acids: a monoenoic acid, oleic acid (C18:1) and a dienoic acid, linoleic acid (C18:2).

The results obtained for fatty acid profiles of the babassu oils are in accordance with data reported in the literature, ${ }^{21-26}$ in particular the lauric acid (C12:0) contents which showed variation from 44.86 to $52.15 \%$ and highest predominance in Orbignya sp oils. The salts prepared from lauric acid have a chemical structure that favors a balance of hydrophiliclipophilic action, suitable for use in the detergent industry. ${ }^{27}$ Table 4 shows fatty acid chemical composition of babassu nuts (Orbignya $\mathrm{sp}$ ) reported in the literature. ${ }^{21-26}$

The Codex Alimentarius, an international standard for food and drugs, shows the main quality parameters of babassu oils from Orbignya sp., a standardized species. The Resolution RDC 270 No. 482 (September 23, 1999) from the Brazilian National Health Surveillance Agency (Agência Nacional de Vigilância Sanitária, ANVISA), ${ }^{28}$ which regulates the quality and authenticity of babassu oil, also adopts this standard. These parameters, compared

Table 3. Fatty acid composition (\%) of babassu oils from different cities of Maranhão State (Brazil)

\begin{tabular}{|c|c|c|c|c|c|c|c|c|}
\hline \multirow{2}{*}{ Fatty acid } & \multirow{2}{*}{$\mathrm{t}_{\mathrm{R}} / \min$} & \multirow{2}{*}{$\mathrm{SI} / \%$} & \multicolumn{6}{|c|}{ City } \\
\hline & & & SL & EPT & FOR & RIA & PEN & IMP \\
\hline Caprylic (C8:0) & $11.47 \pm 0.11$ & 92 & 5.03 & 0.97 & 2.65 & 4.54 & 0.52 & 2.32 \\
\hline Capric (C10:0) & $9.18 \pm 0.09$ & 91 & 5.89 & 2.54 & 3.35 & 7.99 & 2.32 & 3.03 \\
\hline Lauric (C12:0) & $24.53 \pm 0.19$ & 91 & 46.89 & 46.96 & 46.53 & 48.93 & 52.15 & 44.86 \\
\hline Myristic (C14:0) & $30.21 \pm 0.09$ & 91 & 16.95 & 16.89 & 16.91 & 15.64 & 16.58 & 17.57 \\
\hline Palmitic (C16:0) & $35.42 \pm 0.05$ & 93 & 7.98 & 9.86 & 9.13 & 7.46 & 8.63 & 9.44 \\
\hline Linoleic (C18:2) & $37.82 \pm 0.03$ & 94 & 1.34 & 1.86 & 1.72 & 1.65 & 1.53 & 1.67 \\
\hline Oleic (C18:1) & $37.95 \pm 0.04$ & 95 & 13.54 & 17.82 & 16.51 & 10.55 & 15.13 & 17.96 \\
\hline Stearic (C18:0) & $38.23 \pm 0.02$ & 93 & 2.38 & 3.10 & 3.20 & 3.24 & 3.14 & 3.15 \\
\hline$\Sigma$ Saturated & & & 85.12 & 80.32 & 81.77 & 87.80 & 83.34 & 80.37 \\
\hline$\Sigma$ Unsaturated & & & 14.88 & 19.68 & 18.23 & 12.20 & 16.66 & 19.63 \\
\hline Total & & & 100 & 100 & 100 & 100 & 100 & 100 \\
\hline
\end{tabular}

$\mathrm{t}_{\mathrm{R}}$ : retention time; SI: similarity index; $\Sigma$ Saturated: sum of saturated fatty acids; $\Sigma$ Unsaturated: sum of unsaturated fatty acids; SL: São Luís; EPT: Esperantinópolis; FOR: Fortuna; RIA: Riachão; PEN: Penalva; IMP: Imperatriz.

Table 4. Typical fatty acid composition $(\%)$ of babassu oils ${ }^{21-26}$

\begin{tabular}{|c|c|c|c|c|c|c|}
\hline \multirow{2}{*}{ Fatty acid } & \multicolumn{6}{|c|}{ Fatty acid composition / \% } \\
\hline & Martin and Guichard ${ }^{21}$ & Chow $^{22}$ & Rossel1 $^{23}$ & Ferreira et al. $^{24}$ & Codex Alimentarius $^{25}$ & Lima et al. ${ }^{26}$ \\
\hline Caproic(C6:0) & nd & 0.4 & nd & 3.3 & nd & $\mathrm{nd}$ \\
\hline Caprylic(C8:0) & nd & 5.3 & 5.5 & 9.2 & $2.6-7.3$ & 6.0 \\
\hline Capric(C10:0) & nd & 5.9 & 5.5 & 9.6 & $1.2-7.6$ & 5.0 \\
\hline Lauric(C12:0) & $44-47$ & 44.2 & 43.0 & 54.7 & $40.0-55.0$ & 44.0 \\
\hline Myristic(C14:0) & $15-18$ & 15.8 & 16.0 & 11.8 & $11.0-27.0$ & 17.0 \\
\hline Palmitic(C16:0) & 6.9 & 8.6 & 9.0 & 4.8 & $5.2-11.0$ & 8.0 \\
\hline Stearic(C18:0) & 3.5 & 2.9 & 3.5 & 2.05 & $1.8-7.4$ & $4-5$ \\
\hline Oleic(C18:1) & $12-16$ & 15.1 & 15.0 & 6.5 & $9.0-20.0$ & 14.0 \\
\hline Linoleic(C18:2) & $1-2$ & 1.7 & 2.6 & 0.9 & $1.4-6.6$ & 2.0 \\
\hline
\end{tabular}

nd: not detected. 
with the results obtained in this work for the species of $O$. phalerata, show that the percentage (\%) of caprylic acid C8:0 of the samples from Esperantinópolis, Imperatriz and Penalva, was lower than the Codex Alimentarius values, ${ }^{25}$ while the babassu nut sample from Riachão presented a percentage of capric acid C10:0 higher than the Codex Alimentarius, and the samples from São Luís and Fortuna cities were in agreement.

The classification of $O$. phalerata nuts from different regions of Maranhão State was performed using fatty acid composition by exploratory data analysis. The multivariate analysis of PCA and HCA are used for pattern recognition non-supervisioned. The chemical information subserves a better visualization of similarity between samples and infers about possible differences promoted by the variables in the study. ${ }^{29-31}$

The fatty acid contents found on different samples of babassu oils obtained by chromatographic analysis were submitted to the PCA method. Initially, the numbers of principal components (PCs) that describe the original data were selected based on the percentage of variance explained. PCA demonstrated that a small number of variables dominates the total data variability, as the three first PCs accounted for $97.35 \%$ of the total variability. The first component is responsible for $56.99 \%$, the second accounts for $25.28 \%$, and the third explains $15.09 \%$ of the total information.

The PCA plot (Figure 3), considering the contribution or weight for each measurement, shows that $\mathrm{PC} 1$ separates the babassu nut oils according to the content of palmitic (0.986), oleic (0.972) and capric (-0.916); caprylic $(-0.803)$ and myristic $(0.709)$ fatty acids. In PC2, the samples were grouped in relation to the content of stearic $(0.792)$, myristic $(-0.670)$ and lauric $(0.674)$ acids, while in PC3, the samples were divided as to lesser or greater amount of lauric acid (-0.664) and linoleic acid (0.574).

The babassu oil samples from Fortuna (FOR), Esperantinópolis (EPT) and Imperatriz (IMP) showed similar chemical composition, considering the major and minor fatty acids, as shown in the graph PCA scores (Figure 3). The oil sample from São Luís (SL) differs from the others due to its higher content of minor fatty acids, caprylic (C8:0) and capric (C10:0) and lower content of oleic acid (C18:1). In turn, the babassu oil from Riachão (RIA) showed a higher content of caprylic acid (C8:0) and the lowest content of palmitic (C16:0) and oleic (C18:1) acids.

Figure 4 shows the PCA plot of the first three principal components: a three dimensional representation of the PCA analysis. In this representation, the similarity of the oil samples promotes a clear division of the Maranhão State in three regions: Penalva and São Luís in the North;
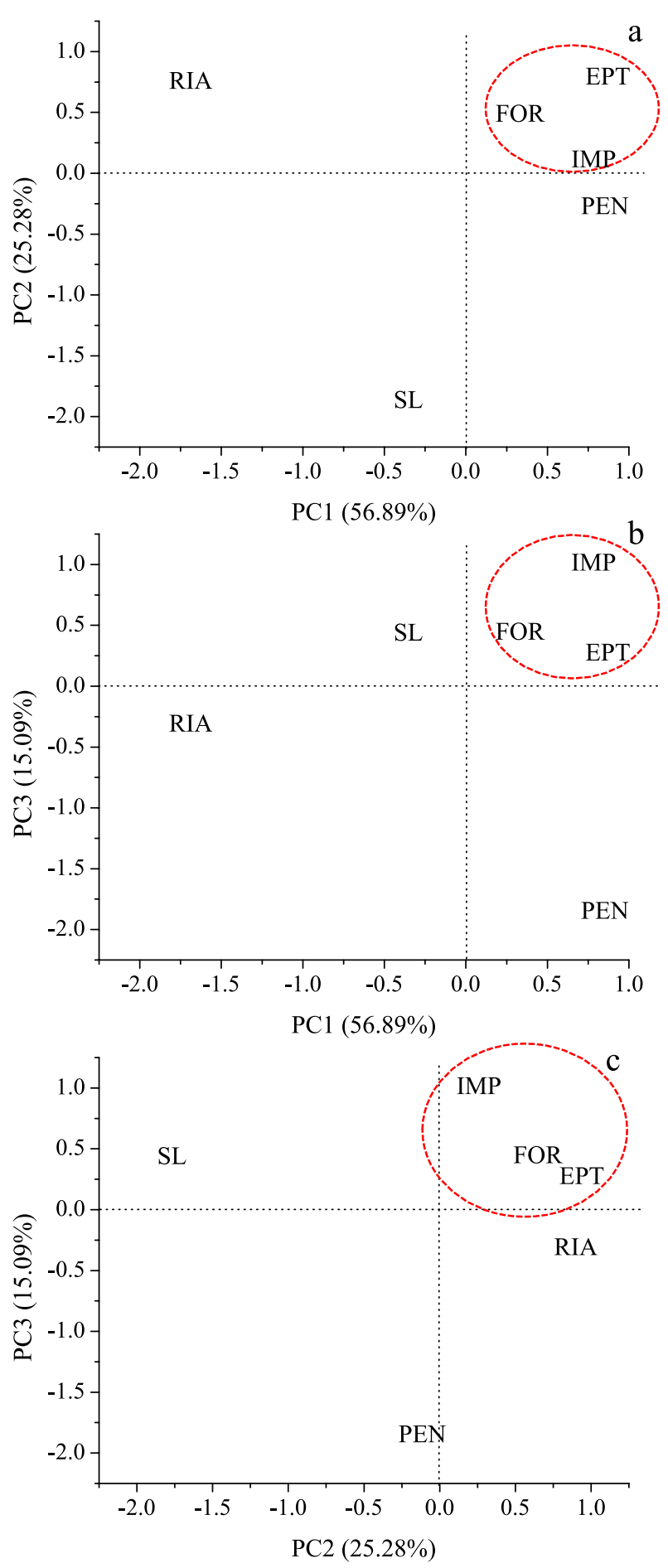

Figure 3. PCA score plot of babassu nuts: (a) PC1 vs. PC2, (b) PC1 vs. PC3 and (c) PC2 vs. PC3. Esperantinópolis (EPT), Fortuna (FOR), Imperatriz (IMP), Penalva (PEN), Riachão (RIA) and São Luís (SL).

Imperatriz, Fortuna and Esperantinópolis in the Central region; and Riachão in the South. The division observed in the 3D PCA plot (Figure 4) is comparable to Figure 1, map of the distribution of six $O$. phalerata samples in Maranhão State, which indicates that the chemical composition of the oils is associated with their geographic location. 


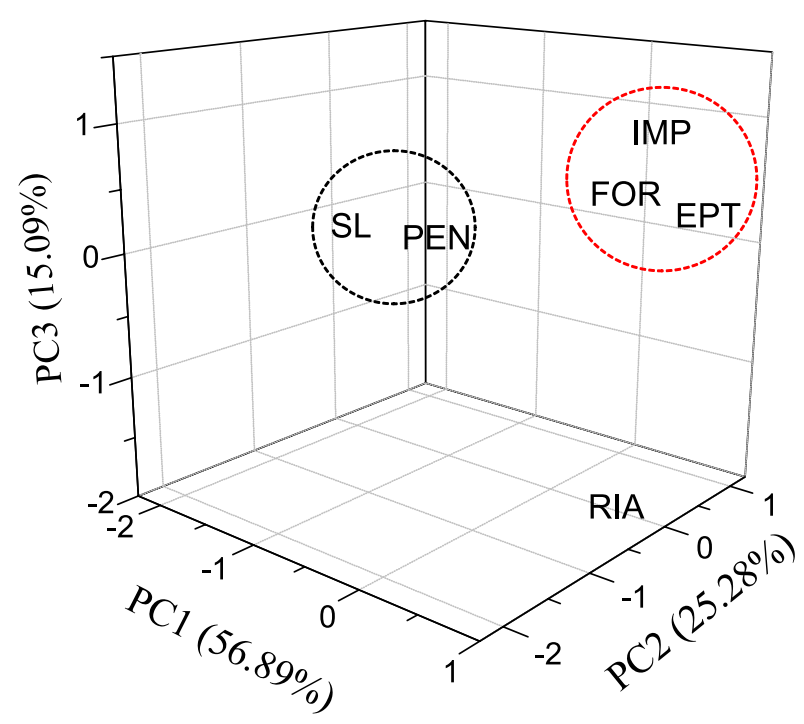

Figure 4. 3D PCA plot, correlation and principal components (PC1 vs. PC2 vs. PC3). Esperantinópolis (EPT), Fortuna (FOR), Imperatriz (IMP), Penalva (PEN), Riachão (RIA) and São Luís (SL).

HCA makes the distinction among babassu oil samples, considering the similarity in the fatty acid contents: the smaller Euclidean distance, the greater the similarity between samples. The HCA dendrogram correlates with the results obtained by PCA plot, PC1 vs. PC2 (Figure 3a), improving visualization of the formed groups. As shown in Figure 5, the babassu oils were classified into three groups, group I containing the samples from Imperatriz (IMP), Fortuna (FOR) and Esperantinópolis (EPT), group II consisting of Penalva (PEN) and São Luís (SL), while the group III is constituted only of Riachão (RIA) sample. These results show that babassu oils of the same geographical region in the Maranhão State (Brazil) have similarities in the fatty acid contents, which may provide useful criteria for geographical origin authentication of babassu nuts. ${ }^{31}$

Euclidean distance
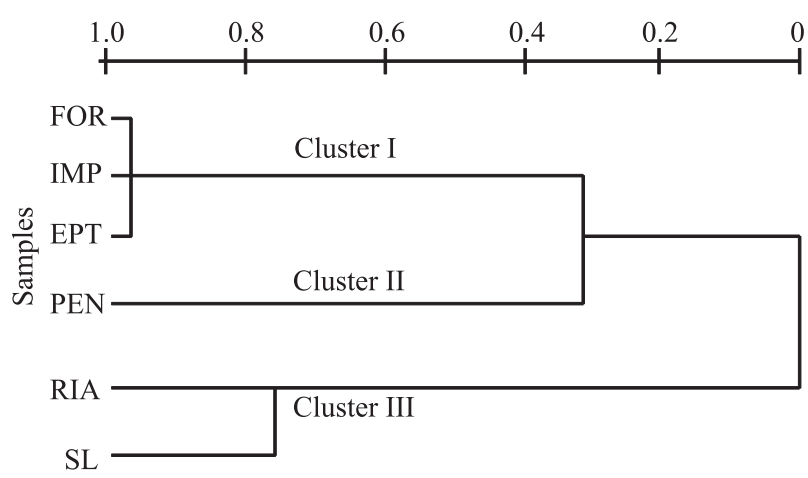

Figure 5. Dendrogram of hierarchical cluster analysis (HCA), Esperantinópolis (EPT), Fortuna (FOR), Imperatriz (IMP), Penalva (PEN), Riachão (RIA) and São Luís (SL).

\section{Conclusions}

The extraction of lipids from babassu nuts (O. phalerata) using the Adolfo Lutz Institute method was the most appropriate methodology for triacylglycerol obtainment. The analyses by GC-MS showed the predominance of saturated fatty acids, with a high lauric acid percentage, the Penalva nuts presented higher content of lauric acid $52.15 \%$. The multivariate analysis methods, PCA combined with HCA, evidenced the similarity of the fatty acid composition of babassu oils from different regions in the Maranhão State, showing the importance of the exploratory data analysis to extract new information from the chemical data. The exploratory data analysis by PCA and HCA allowed to infer that the oils of the same territorial range have similar chemical composition, regardless of the biome. These data indicate knowledge of biodiversity of fatty acids of $O$. phalerata among the regions of the Maranhão State.

\section{Acknowledgments}

The authors thank Coordination for the Improvement of Higher Education Personnel (CAPES, Brazil), National Council for Scientific and Technological Development (CNPq, Brazil) and the Maranhão State Research Foundation (FAPEMA, Brazil) for financial support and research scholarships.

\section{References}

1. Anderson, A. B.; Balick, M. J.; Syst. Botany 1988, 13, 32.

2. Teixeira, M. A.; Biomass Bioenergy 2008, 32, 857.

3. Naozuka, J.; Vieira, E. C.; Nascimento, A. N.; Oliveira, P. V.; Food Chem. 2011, 124, 1667.

4. Instituto Maranhense de Estudos Socioeconômicos e Cartográficos (IMESC); Anuário Estatístico do Maranhão; MESC: São Luís, Brasil, 2010; Instituto Brasileiro de Geografia e Estatística (IBGE); Produção da Extração Vegetal e da Silvicultura. Ministério do Planejamento, Orçamento e Gestão. IBGE: Brasil, 2011.

5. Empresa Brasileira de Pesquisa Agropecuária (EMBRAPA); Babaçu: Programa Nacional de Pesquisa. Brasília; EMBRAPA: Brasília, Brasil, 1984.

6. Souza, M. H. S. L.; Monteiro, C. A.; Figueredo, P. M. S.; Nascimento, F. R. F.; Guerra, R. N. M.; J. Ethnopharmacol. 2011, 133, 1 .

7. Pinto, A. C.; Guarieiro, L. L. N.; Rezende, M. J. C.; Ribeiro, N. M.; Torres, E. A.; Lopes, W. A.; Pereira, P. A. P.; Andrade, J. B.; J. Braz. Chem. Soc. 2005, 16, 1313.

8. Chaves, M. H.; Barbosa, A. S.; Moita Neto, J. M.; Aued-Pimentel, S.; Lago, J. H. G.; Quím. Nova 2004, 27, 404; 
Rodrigues, A. M. C.; Darnet, S.; Silva, L. H. M.; J. Braz. Chem. Soc. 2010, 21, 2000.

9. Kumar, S. N.; J. Agric. Food Chem. 2011, 59, 13050.

10. Seppänen-Laakso, T.; Laakso, I.; Hiltunen, R.; Anal. Chim. Acta 2002, 465, 39.

11. Instituto Adolfo Lutz (IAL); Normas Analíticas do Instituto Adolfo Lutz: Métodos Químicos e Físicos para Análise de Alimentos, $4^{\text {th }}$ ed.; Ministério da Saúde: Brasília, Brasil, 2005.

12. International Union of Pure and Applied Chemistry (IUPAC); Standard Methods for the Analysis of Oils, Fats and Derivatives, $6^{\text {th }}$ ed.; Pergamon Press: Oxford, 1979.

13. Hartman, L.; Lago, R. C. A.; Lab. Pract. 1973, 22, 475.

14. Gunstone, F. D.; Norris, F. A.; Lipids in Foods: Chemistry, Biochemistry and Technology; Pergamon Press: Oxford, UK, 1983.

15. Peixoto, A. R.; Plantas Oleaginosas Arbóreas; Nobel: São Paulo, Brasil, 1973.

16. Soler, M. P.; Vitali, A. A.; Muto, E. F.; Ciênc. Tecnol. Aliment. 2007, 27, 717 .

17. Picciani, J. R. S.; Informações sobre o Babaçu; Serviço Brasileiro de Respostas Técnicas (SBRT), Centro de Apoio ao Desenvolvimento Tecnológico (CDT)/UnB: Brasília, Brasil, 2007.

18. Mani, S.; Jaya, S.; Vadivambal, R.; Food Bioprod. Process. 2007, 85, 328.

19. Khodapanahi, E.; Lefsrud, M.; Orsat, V.; Singh, J.; Warkentin, T. D.; Energies 2012, 5, 3788.

20. Nibbering, N. M. M.; J. Am. Soc. Mass Spectrom. 2004, 15, 956.

21. Martin, G.; Guichard, P. H.; Oleagineux 1979, 34, 375.

22. Chow, C. K.; Fatty Acids in Foods and their Health Implications, $3^{\text {rd }}$ ed.; CRC Press, Taylor \& Francis Group: Lexington, USA, 2007.
23. Ranken, M. D.; Manual de Industrias de los Alimentos, $2^{\text {nd }}$ ed.; Editora Acríbia: Zaragoza, Spain, 1993.

24. Ferreira, B. S.; Faza, L. P.; Le Hyaric, M.; TSWJ 2012, 2012.

25. Codex Alimentarius Commission; Codex Standards for Named Vegetable Oils, CODEX- STAN 210-1999; Food and Agriculture Organization of the United Nations/World Health Organization (FAO/WHO): Rome, Italy, revised in 2009.

26. Lima, J. R. O.; Silva, R. B.; Silva, C. C. M.; Santos, L. S. S.; Santos Junior, J. R.; Moura, E. M.; Moura, C. V. R.; Quím. Nova 2007, 30, 600 .

27. Moretto, E.; Fett, R.; Tecnologia de Óleos e Gorduras Vegetais na Indústria de Alimentos; Livraria Varela: São Paulo, Brasil, 1998.

28. Agência Nacional de Vigilância Sanitária (ANVISA); Regulamento Técnico para Fixação de Identidade e Qualidade de Óleos e Gorduras Vegetais, Resolução RDC No. 482, de 23 de setembro de 1999; Diário Oficial da União: Brasília, Brasil, 1999.

29. Correia, P. R. M.; Ferreira, M. M. C.; Quím. Nova 2007, 30, 481.

30. Ranalli, A.; Pollastri, L.; Contento, S.; Di Loreto, G.; Iannucci, E.; Lucera, L.; Russi, F.; J. Agric. Food Chem. 2002, 50, 3775.

31. Fernandes, A. P.; Santos, M. C.; Lemos, S. G.; Ferreira, M. M. C.; Nogueira, A. R. A.; Nóbrega, J. A.; Spectrochim. Acta, Part B 2005, 60, 717; Arena, E.; Campisi, S.; Fallico, B.; Maccarone, E.; Food Chem. 2007, 104, 403.

Submitted: December 12, 2012 Published online: February 28, 2013 